Z Epileptol 2013 $\cdot 26: 79-84$

DOI 10.1007/s10309-012-0281-3

Published Online: 11. April 2013

(c) Springer-Verlag Berlin Heidelberg 2013

R. Sutter ${ }^{1,2,3} \cdot$ S. Rüegg ${ }^{3}$

${ }^{1}$ Division of Neurosciences Critical Care, Departments of Anesthesiology,

Critical Care Medicine and Neurology, Johns Hopkins University, School of

Medicine and Johns Hopkins Bayview Medical Center, Baltimore

${ }^{2}$ Clinic for Intensive Care Medicine, University Hospital Basel

${ }^{3}$ Division of Clinical Neurophysiology, Department of Neurology, University Hospital Basel

\title{
Predicting outcome in adults with status
} epilepticus

line antiepileptic drugs (AEDs; phenytoin, valproate, or levetiracetam). This condition-defined as refractory SE (RSE) [4] - heralds a prolonged hospitalization and worse prognosis than AED-responsive SE [5]. It is usually associated with potentially fatal etiologies, severe impairment of consciousness, and with a mortality of almost $40 \%$ [6].

Despite the clinical and socioeconomic impact of SE, current knowledge relies almost exclusively on retrospective assessments, and the management of RSE is supported only by small case series and expert opinions. Should patients be treated aggressively with early intubation and high-dose anesthetic drugs, or managed less urgently, even when delayed seizure control might carry the risk of neuronal damage? This decision is complex and has been addressed only in a few studies [7]. A management algorithm which fits all different types of SE is not tenable, as morbidity and mortality differs considerably in dependence of the underlying causes of SE. Knowledge regarding prognosis and its determining factors ( - Tab. 1$)$ is one of the cornerstones for early treatment adaption and tailored management algorithms (• Fig. 1).

\section{Determinants of outcome in status epilepticus}

\section{Etiology of status epilepticus and outcome}

Estimates of SE and RSE mortality vary, as neurofunctional outcome and mortality mainly depend on the underlying etiology and whether SE following hypoxicischemic encephalopathy is included in the study [8]. Therefore, early guidelines of the International League Against Epilepsy (ILAE) proposed a categorization of SE according to the underlying etiology with the aim to allow comparison between future epidemiologic and epilepto-

\begin{tabular}{l}
$\begin{array}{l}\text { Tab. } 1 \text { Determinants of outcome in sta- } \\
\text { tus epilepticus }\end{array}$ \\
\hline Demographics and clinical characteristics \\
\hline Etiology \\
\hline History of epilepsy \\
\hline Age \\
\hline $\begin{array}{l}\text { Level of consciousness at status epilepticus } \\
\text { onset }\end{array}$ \\
\hline Status epilepticus characteristics \\
\hline Seizure type at status epilepticus onset \\
\hline Duration of status epilepticus \\
\hline Treatment characteristics \\
\hline Treatment delay \\
\hline Adverse events \\
\hline Complications during status epilepticus \\
\hline
\end{tabular}




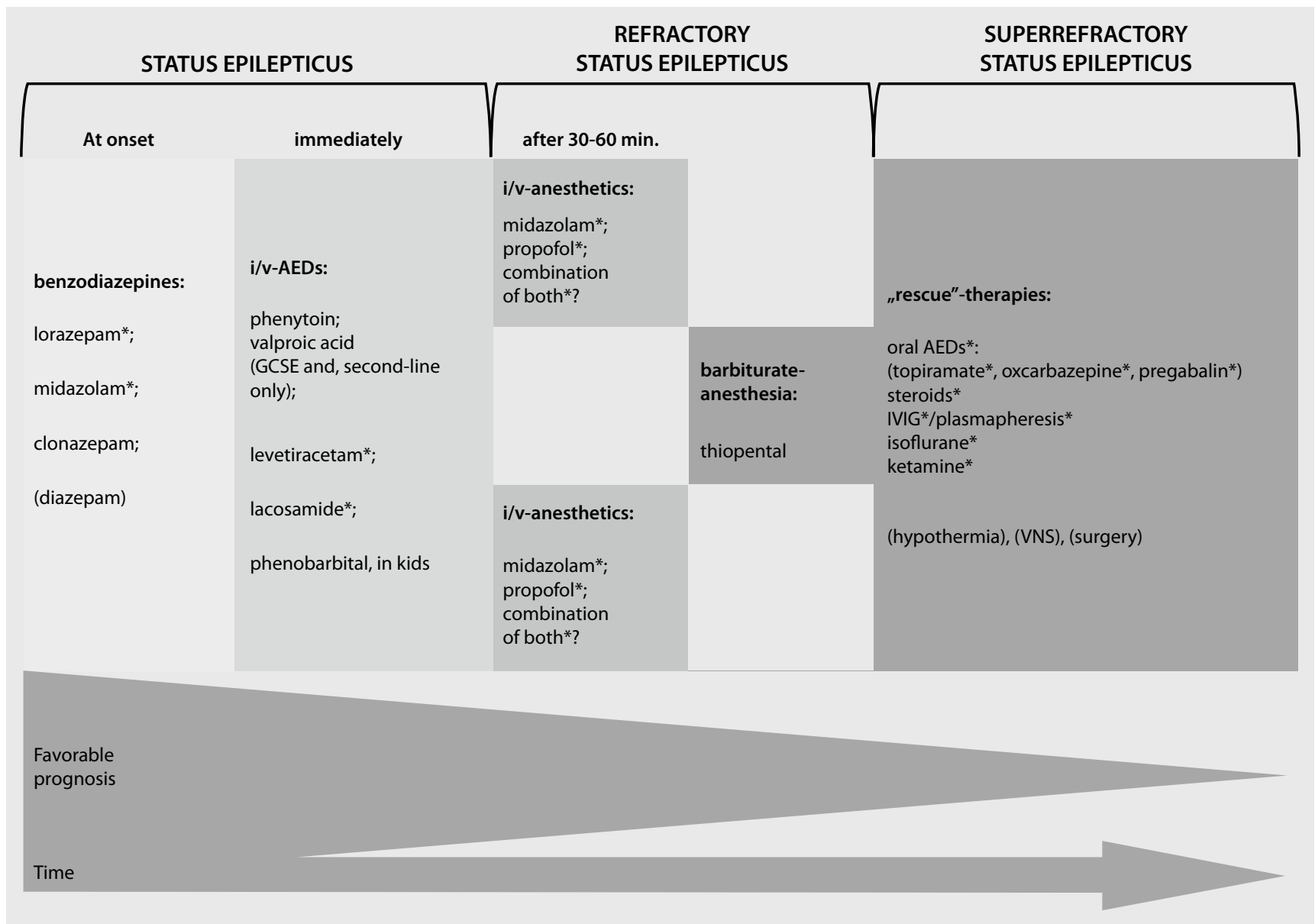

Fig. $1 \Delta$ Treatment algorithm for status epilepticus. AED antiepileptic drug, GCSE generalized convulsive status epilepticus, VNS vagal nerve stimulation, IVIG intravenous immunoglobulines. *Drugs not approved for treatment of status epilepticus

logic studies on SE [9]. Accordingly, SE was classified as

- acute symptomatic,

- remote symptomatic,

- progressive symptomatic, and

- idiopathic/cryptogenic.

Mortality following SE in patients with known epilepsy and insufficient AED levels is low (3\%), while it is higher $(27 \%)$ in patients with SE from secondary causes, suggesting that the epileptic activity itself has no significant contribution to morbidity [10]. With absence SE (ASE), there has been no demonstrated fixed deficit, even after prolonged SE and in de novo complex partial SE caused by cerebral insults, there is little evidence and no consensus on seizure-related morbidity [11]. In contrast, acute symptomatic etiologies have been consistently linked to poor outcome [12]. Persistent seizure activity following hypoxic-ischemic encephalopathy is an independent predictor of poor outcome with a mortality of up to $100 \%$, mainly because of its largely irreversible brain damage [13]. In a recent study on 111 ICU patients with RSE, hypoxic-ischemic encephalopathy and brain tumors were independently associated with high relative risks (RR) for death (RR 2.41, 95\% confidence interval [CI] 1.40-4.12 and RR 2.81, 95\%CI 1.59-4.96) [14]. Regarding brain tumors, different results come from a study on the detection and treatment of RSE in the ICU which revealed an improvement of the level of consciousness in all patients with brain tumors on anticonvulsants [15]. However, the proportion of patients $(4 \%)$ with brain tumors was small.

\section{History of epilepsy and outcome}

The majority of SE is thought to develop without a prior history of epilepsy [16], and almost always secondary to an underlying structural or metabolic-toxic pathology [17]. In a 5-year observational study of $160 \mathrm{ICU}$ patients with SE, epilepsy was known and diagnosed prior to SE onset in $15 \%$ [18]. In a prospective study on $154 \mathrm{SE}$ patients from 3 sites, seizure history at SE onset, a surrogate for no acute and fatal SE etiologies, was identified as an independent factor for survival in the multivariable analysis (odds ratio [OR] for death 0.23, 95\%CI 0.08-0.65) [19].

\section{Age and outcome}

Older age has been associated with unfavorable outcome of SE in many studies [20]. These studies were contrasted by a recent retrospective cohort study of 106 patients with 111 SE episodes, which revealed no significant difference in case fatality rate between SE of patients younger and older than 70 years but a 
statistically significant risk for younger patients to develop prolonged and more severe SE course [21]. Moreover, older age was independently associated with a more favorable SE course in the multivariate analysis. A potential bias in this context may have been that a substantial proportion of the older age group died before reaching the hospital or before the diagnosis of SE could be established (referral bias). Another explanation may be that younger people (1) occasionally develop an "idiopathic" severe SE, labeled "malignant SE" and (2) might have a higher threshold for SE, which might be more difficult to overcome. Furthermore, older patients were probably more likely to be sent to the hospital and to be admitted to the ICU, even if they were not as sick as the younger patients, but because they were potentially at greater risk to require more rapid and intensified treatment. However, in a prospective multicenter study on 154 SE patients that validated the predictive power of a clinical outcome score, older age was identified as an independent factor for death (OR 1.03, 95\%CI 1.00-1.06) [19].

\section{Time to treatment of status epilepticus and outcome}

The question if ongoing epileptic activity may in some conditions cause brain damage and have an effect on outcome has been addressed in several studies. However, animal models could not provide a clear answer, as most models have been used to investigate the effects of SE, by inducing brain insults that cause chronic neuronal damage by themselves. Models to investigate excitotoxicity have used powerful chemoconvulsants or prolonged high-frequency repetitive stimulation in nonepileptic animals [22, 23]. In humans, there is only little data since it would be ethically barely possible to conduct a study comparing immediate start of treatment with delayed initiation of therapy. Retrospective studies may be open to several biases and might be hampered by the lack of accurate data ascertainment as the start of SE, especially its nonconvulsive forms, often remains undetected for a long while and, therefore, has to be roughly estimated what impairs reliability. A clear relationship between duration of SE before administration of first-line treatment and response to this treatment was observed in a retrospective single center study of the urban area of San Francisco in the 1980s. The duration of $S E$ in responders was $0.7 \pm 0.7 \mathrm{~h}$, in nonresponders $1.08 \pm 1.41 \mathrm{~h}-\mathrm{a}$ difference that was significant $(\mathrm{p}=0.05)$ [24].

\section{Consciousness at the start of status epilepticus and outcome}

A study which aimed to identify prognostic factors in a hospital-based, adult population with SE revealed that at the initial evaluation, impairment of consciousness, and older age were predictive of death [25]. A recent study of mortality and recovery from RSE in ICU patients found that nonsurvivors had significant higher levels of consciousness at SE onset than survivors (10\% awake or somnolent vs. $33 \%$ awake or somnolent; $\mathrm{p}=0.006)$-a relation that was no longer significant after excluding patients with hypoxic-ischemic encephalopathy ( $16 \%$ vs. $38 \%$; $p=0.072$ ), although NCSE in coma remained independently associated with death (RR 3.62, 95\%CI 1.349.77) [14]. Altered level of consciousness in the course of SE or induced by anesthetic third-line drugs such as pentobarbital, midazolam, propofol, and highdose phenobarbital necessitate intubation, mechanical ventilation. Systematic reviews concluded that coma induction with barbiturates effectively terminates seizures, but delays the recovery from coma and prolongs ventilator treatment and intensive care [26].

\section{Seizure type at status epilepticus onset and outcome}

In our study on 111 ICU patients with RSE, nonconvulsive SE (NCSE) in coma was independently associated with high relative risks for death (RR 3.62, 95\%CI 1.34-9.77) [14] - a result which underscores the results of previous studies. In these studies, patients with complex partial, myoclonic or absence or simple partial seizures showed no association with poor outcome, while presence of NCSE in coma and generalized convulsive sei-
Z Epileptol 2013 - 26:79-84

DOI 10.1007/s10309-012-0281-3

๑) Springer-Verlag Berlin Heidelberg 2013

\section{R. Sutter · S. Rüegg}

Predicting outcome in adults with status epilepticus

\section{Abstract}

Status epilepticus (SE) is a life-threatening state of persisting or repetitive seizure activity with often permanent altered level of consciousness. Despite its high morbidity and mortality there is no consensus about the best strategy to treat specific forms of SE. The compromise between the danger related to untreated and persistent seizure activity and the possible damage induced by unnecessary aggressive treatments is challenging. Knowledge about the determinants and reliable prediction models of outcome early in the course of SE is fundamental for rapid treatment modulation and for planning the level of monitoring. This review compiles the current evidence for outcome prediction based on clinical determinants in adult SE patients.

\section{Keywords}

Status epilepticus · Mortality · Recovery .

Prognosis · Neurocritical care

\section{Prognosestellung bei erwachsenen Patienten mit Status epilepticus}

\section{Zusammenfassung}

Der Status epilepticus (SE) stellt einen lebensbedrohlichen Zustand mit einer meist anhaltenden oder repetitiven epileptischen Aktivität und persistierenden Vigilanzminderung dar. Trotz der mit SE verbundenen hohen Morbidität und Mortalität gibt es keinen Konsensus bezüglich der besten Behandlungsstrategie für die einzelnen Formen von SE. Der Kompromiss zwischen der Gefahr einer anhaltenden, unbehandelten epileptischen Aktivität und der potentiellen Schädigung des Patienten durch unnötig aggressive Behandlung bedeutet eine große Herausforderung. Kenntnisse über die prognostisch relevanten Determinanten und über Prädiktionsmodelle, die eine frühe prognostische Einschätzung erlauben, sind für die rasche Behandlungsanpassung und das Ausmaß der Patientenüberwachung entscheidend. Diese Übersichtsarbeit stellt die wichtigsten Prädiktionsmodelle und deren zugrunde liegenden klinischen Determinanten für erwachsene SEPatienten zusammen.

\section{Schlüsselwörter}

Status epilepticus · Mortalität · Erholung ·

Prognose $\cdot$ Neurokritische Behandlung 
Tab. 2 The integral components of the

Status Epilepticus Severity Score (STESS).

(Adapted from [35])

Clinical features

Score

Level of consciousness at SE onset

\begin{tabular}{ll} 
Alert or somnolent/confused & 0 \\
\hline Stuporous or comatose & 1
\end{tabular}

\section{Worst seizure type at SE onset}

Simple partial/complex/absence 0

Generalized convulsive

NCSE in coma 2

\section{Age at SE onset}

$\begin{array}{ll}<65 \text { years of age } & 0 \\ \geq 65 \text { years of age } & 2\end{array}$

History of seizures at SE onset

Prior seizures 0

No prior seizures

1

SE status epilepticus, NCSE nonconvulsive status epilepticus.

zures at SE onset were significantly associated with high odds for death (OR 5.80, 95\%CI 2.11-15.90). In addition, compared with people with a first brief unprovoked seizure, the adjusted relative risk for death in those with SE was 2.4 (95\%CI 0.9-6.3) over 10 years [20].

A prospective population-based study in Richmond, Virgina, found a significantly lower mortality in patients with intermittent SE when compared to those with continuous SE (19.6 vs. $31.4 \%$; $\mathrm{p}<0.001$ ). Further analysis revealed a significantly and independently increased relative risk of death ( RR 1.79; $\mathrm{p}=0.04$ ) in patients with continuous SE after adjusting for SE type (continuous vs. intermittent), age, etiology, and SE duration [27].

\section{Status epilepticus duration and outcome}

In a 3-year observational study, hospital stay increased by $1.13 \mathrm{~h}$ with each additional hour of seizure activity $(\mathrm{p}=0.02)$ and SE duration was significantly longer in patients with unfavorable course of SE (defined as death before discharge and/ or RSE). This study was followed by an investigation on a cohort of 160 SE patients which revealed that seizure duration was significantly longer in patients with infections during SE $(\mathrm{p}<0.0001)$; however, it could not be determined whether infections were the cause or the result of prolonged seizure activity-a limitation of retrospective study design [18]. In studies on RSE, seizure duration was significantly longer in nonsurvivors compared to survivors [28] and seizure duration was independently associated with high relative risks for death; however, the relative risk was only minimal of every additional hour of SE (for every hour: RR 1.001, 95\%CI 1.00-1.002) [14]. Furthermore, differences in seizure duration between survivors and nonsurvivors tended to be more distinct in patients with uncontrolled epilepsy in contrast to more severe etiologies of SE, such as brain tumors and hypoxic-ischemic encephalopathy. These findings suggest that the impact of seizure duration on outcome tends to decrease in the presence of an underlying, severe etiology of SE [14].

\section{Complications during status epilepticus and outcome}

Complications during the course of SE have not been investigated frequently. In a study on the incidence of infections during SE and their effect on resource utilization [29], infections resulted in a 4 -fold increase of the use of nursing resources and significant prolongation of ICU stay. However, further analyses regarding the types and influences of infections on SE course and outcome, as well as their correlation with time of SE onset, were not performed. A study on 160 consecutive SE patients revealed that $23 \%$ of patients had infections during the course of SE [18]a similar incidence $(24 \%)$ as reported by a large U.S. cohort study of patients with generalized convulsive SE [30]. Of those, $94 \%$ were respiratory tract infections and $29 \%$ were ventilator-associated pneumonias with a predominance in patients with NCSE-possibly explained by a higher risk of aspiration because of the mostly longer period of unrecognized seizure activity in patients with altered consciousness compared with patients with convulsive SE [31]. The presence of infections during SE was significantly associated with longer seizure duration $(\mathrm{p}<0.0001)$, longer ICU stay ( $\mathrm{p}=0.0041)$, higher risk of RSE (OR 4.8; 95\%CI 2.8-10.9), and higher mortality (OR 5.2; 95\%CI 2.11-12.7) [18].
Complications are increasingly recognized in conjunction with the use of anesthetic drugs in SE. Phenobarbital and pentobarbital were associated with cardiotoxicity, thiopental with severe hypotension, and propofol with hepatotoxicity and metabolic acidosis with rhabdomyolysis and cardiac failure (i.e., propofol infusion syndrome [32]). A recent study of 126 patients with mainly convulsive SE revealed an association of the administration of continuously administered i.v. anesthetic drugs with poor outcome, while treatment with pentobarbital was linked to the longest duration of mechanical ventilation, and to the highest frequency of severe hypotension requiring vasopressors [33]. However, interpretation of these results are impeded by the lack of adjustment for possible confounders, such as the fact that physicians may tend to favor anesthetics as a "rescue therapy" in patients with particular clinical and EEG characteristics (confounding by indication). Conversely, prolonged use of i.v. anesthetic drugs might be withheld from patients with critical medical conditions if their physicians judge them not to be "fit enough" to survive such treatment. Prospective studies on more homogenous cohorts with patients with RSE treated with nonsedating 3rd-line AEDs vs. patients with i.v. anesthetics as the third drug are needed to strengthen or revoke these results.

\section{Scoring systems}

The main goal in the treatment of SE patients is the early AED administration and rapid treatment adaption, tailored to the severity of SE and the expected prognosis. One study using the APACHE-II score (a prognostic scoring system for ICU patients based on underlying disease, chronic conditions, and physiologic variables) for RSE patients, found a high initial APACHE-II score to be an independent predictor for death [34]. However, this association was only seen in patients suffering from RSE.

In 2006 a Swiss study group [35] developed a scoring system for early outcome prediction in SE patients (• Tab. 2). This Status Epilepticus Severity Scale (STESS) was based on the associations of specific 
etiologies, older age, and consciousness impairment at SE onset with death and a history of survived SE with a decreased mortality in SE patients in a prior study [25]. STESS promises to provide a rational for predicting outcome and planning the level of monitoring and possibly modulating the aggressiveness of treatment early in the course of SE [35]. This clinical scoring system was validated in a prospective multicenter study [19]. However, one of the sites was the same where STESS was generated and the study was conducted and analyzed by the same investigators who developed STESS, possibly impeding the generalizability of their results. Further external and independent validation is needed to further strengthen the reliability of STESS for early outcome prediction.

\section{Clinical practice points}

- To the current knowledge, acute and life-threatening etiology (e.g., postanoxic encephalopathy, brain tumors, herpes encephalitis) is the main factor contributing to poor outcome in patients with SE.

- Other factors pointing to a worse outcome seem to be: level of consciousness at SE onset, duration of SE, delay of treatment, continuous vs. intermittent SE and complications, especially infections.

- While the influence of older age is discussed equivocally, a history of epilepsy is likely to be associated with a favorable outcome.

- Scores which could be easily and reliably assessed at the beginning of SE and which would predict outcome with high accuracy are highly welcome. The so-called STESS score hereby seems to be a first step in this direction. STESS has been validated not only internally, but will also be externally in the very near future.

\section{Corresponding address}

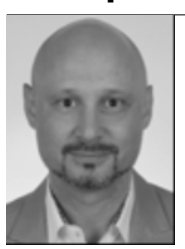

\section{R. Sutter}

Division of Neurosciences

Critical Care, Departments

of Anesthesiology,

Critical Care Medicine and

Neurology,

Johns Hopkins University

School of Medicine and

Johns Hopkins Bayview

Medical Center

301 Mason Lord Drive, Suite

2100, 21224 Baltimore

$M D$

USA

rsutter3@jhmi.edu

Conflicts of interest. On behalf of all authors, the corresponding author states the following: R.S. is supported by the Research Funds of the University of Basel, the Scientific Society Basel, and the Gottfried Julia Bangerter-Rhyner Foundation. S.R. received unconditional research grants from UCB. He received honoraria from serving on the scientific advisory boards of Eisai and UCB, travel grants from GSK, Janssen-Cilag, UCB, speaker fees from UCB and from serving as a consultant for Eisai, GlaxoSmithKline, Janssen-Cilag, Pfizer, Novartis, and UCB. He does not hold any stocks of any pharmaceutical industries or manufacturers of medical devices.

\section{References}

1. Knake S, Rosenow F, Vescovi M et al (2001) Incidence of status epilepticus in adults in Germany: a prospective, population-based study. Epilepsia 42(6):714-718

2. De Lorenzo RJ (1997) Clinical and epidemiologic study of status epilepticus in the elderly. In: Rowan AJ, Ramsay RE (eds) Seizures and epilepsy in the elderly. Butterworth-Heinemann, Boston, pp 191-205

3. DeLorenzo RJ, Pellock JM, Towne AR et al (1995) Epidemiology of status epilepticus. J Clin Neurophysiol 12(4):316-325

4. Lowenstein DH, Alldredge BK (1998) Status epilepticus. N Engl J Med 338(14):970-976

5. Rossetti AO, Logroscino G, Bromfield EB (2005) Refractory status epilepticus: effect of treatment aggressiveness on prognosis. Arch Neurol 62(11):1698-1703

6. Novy J, Logroscino G, Rossetti AO (2010) Refractory status epilepticus: a prospective observational study. Epilepsia 51(2):251-256

7. Ferguson M, Bianchi MT, Sutter R et al (2012) Calculating the risk benefit equation for aggressive treatment of non-convulsive status epilepticus. Neurocrit Care (epub ahead of print)

8. Chin RFM, Neville BGR, Scott RC (2004) A systematic review of the epidemiology of status epilepticus. Eur J Neurol 11(12):800-810

9. Commission on Epidemiology and Prognosis ILAE (1993) Guidelines for epidemiologic studies on epilepsy. Epilepsia 34(4):592-596

10. Shneker BF, Fountain NB (2003) Assessment of acute morbidity and mortality in nonconvulsive status epilepticus. Neurology 61(8):1066-1073
11. Kaplan PW (1999) Assessing the outcomes in patients with nonconvulsive status epilepticus: nonconvulsive status epilepticus is underdiagnosed, potentially overtreated, and confounded by comorbidity. J Clin Neurophysiol 16(4):341352 (discussion 53)

12. Claassen J, Lokin JK, Fitzsimmons BFM et al (2002) Predictors of functional disability and mortality after status epilepticus. Neurology 58(1):139-142

13. Rossetti AO, Logroscino G, Liaudet L et al (2007) Status epilepticus: an independent outcome predictor after cerebral anoxia. Neurology 69(3):255-260

14. Sutter R, Marsch S, Fuhr P et al (2013) Mortality and recovery from refractory status epilepticus in the ICU: a 7-year observational study. Epilepsia. doi: 10.1111/epi.12064

15. Drislane FW, Lopez MR, Blum AS et al (2008) Detection and treatment of refractory status epilepticus in the intensive care unit. J Clin Neurophysiol 25(4):181-186

16. DeLorenzo RJ, Hauser WA, Towne AR et al (1996) A prospective, population-based epidemiologic study of status epilepticus in Richmond, Virginia. Neurology 46(4):1029-1035

17. Aminoff MJ, Simon RP (1980) Status epilepticus: causes, clinical features and consequences in 98 patients. Am J Med 69(5):657-666

18. Sutter R, Tschudin-Sutter S, Grize L et al (2012) Associations between infections and clinical outcome parameters in status epilepticus: a retrospective 5 -year cohort study. Epilepsia 53(9):1489-1497

19. Rossetti AO, Logroscino G, Milligan TA et al (2008) Status Epilepticus Severity Score (STESS): a tool to orient early treatment strategy. J Neurol 255(10):1561-1566

20. Logroscino G, Hesdorffer DC, Cascino $G$ et al (2008) Status epilepticus without an underlying cause and risk of death: a population-based study. Arch Neurol 65(2):221-224

21. Rudin D, Grize L, Schindler C et al (2011) High prevalence of nonconvulsive and subtle status epilepticus in an ICU of a tertiary care center: a three-year observational cohort study. Epilepsy Res 96(1-2):140-150

22. Covolan L, Ribeiro LT, Longo BM et al (2000) Cell damage and neurogenesis in the dentate granule cell layer of adult rats after pilocarpine- or kainate-induced status epilepticus. Hippocampus 10(2):169-180

23. Mazarati AM, Baldwin RA, Sankar R et al (1998) Time-dependent decrease in the effectiveness of antiepileptic drugs during the course of selfsustaining status epilepticus. Brain Res 814(12):179-185

24. Lowenstein DH, Alldredge BK (1993) Status epilepticus at an urban public hospital in the 1980s. Neurology 43(3):483-488

25. Rossetti AO, Hurwitz S, Logroscino G et al (2006) Prognosis of status epilepticus: role of aetiology, age, and consciousness impairment at presentation. J Neurol Neurosurg Psychiatry 77(5):611615

26. Prabhakar H, Bindra A, Singh GP et al (2012) Propofol versus thiopental sodium for the treatment of refractory status epilepticus. Cochrane Database Syst Rev 8:CD009202

27. Waterhouse EJ, Garnett LK, Towne AR et al (1999) Prospective population-based study of intermittent and continuous convulsive status epilepticus in Richmond, Virginia. Epilepsia 40(6):752-758 


\section{Main topic}

28. Drislane FW, Blum AS, Lopez MR et al (2009) Duration of refractory status epilepticus and outcome: loss of prognostic utility after several hours. Epilepsia 50(6):1566-1571

29. Ala-Kokko TI, Säynäjäkangas $P$, Laurila $P$ et al (2006) Incidence of infections in patients with status epilepticus requiring intensive care and effect on resource utilization. Anaesth Intensive Care 34(5):639-644

30. Koubeissi M, Alshekhlee A (2007) In-hospital mortality of generalized convulsive status epilepticus: a large US sample. Neurology 69(9):886893

31. Privitera M, Hoffman M, Moore JL et al (1994) EEG detection of nontonic-clonic status epilepticus in patients with altered consciousness. Epilepsy Res 18(2):155-166
32. Guitton C, Gabillet L, Latour P et al (2011) Propofol Infusion syndrome during refractory status epilepticus in a young adult: successful ECMO resuscitation. Neurocrit Care 15(1):139-145

33. Wong JM (2010) Propofol infusion syndrome. Am J Ther 17(5):487-491

34. Prasad A, Worrall BB, Bertram EH et al (2001) Propofol and midazolam in the treatment of refractory status epilepticus. Epilepsia 42(3):380-386

35. Rossetti AO, Logroscino G, Bromfield EB (2006) A clinical score for prognosis of status epilepticus in adults. Neurology 66(11):1736-1638

\section{Hier steht eine Anzeige.}

\section{Springer}

